\title{
Immediate effects of TENS and cryotherapy in the reflex excitability and voluntary activity in hemiparetic subjects: a randomized crossover trial
}

\author{
Efeitos imediatos da TENS e crioterapia na excitabilidade reflexa e atividade \\ voluntária de sujeitos hemiparéticos: um estudo controlado aleatorizado cruzado
}

Fábio L. Martins', Luis C. Carvalho',2, Cassiane C. Silva', Jamilson S. Brasileiro³, Túlio O. Souza ${ }^{3}$, Ana R. R. Lindquist ${ }^{3}$

\begin{abstract}
Background: The disorder of reflex and motor function in patients affected by stroke causes negative impact on the performance of movement patterns and affects the functional activities. Objectives: To investigate the immediate effects of transcutaneous electrical nerve stimulation (TENS) and cryotherapy interventions on the spinal reflex excitability and in the voluntary electromyography (EMG) activity in people with chronic stroke. Method: Randomized crossover trial. The maximum H-reflex (Hmax), the H-reflex latency and the maximum motor response (Mmax) of the soleus muscle and also the EMG of the tibialis muscle where evaluated before and after the application of TENS, cryotherapy and control conditions. Results: The Hmax/Mmax ratio was statistically significant higher ( $p=0.0245)$ and the H-reflex latency was statistically significant lower $(p=0.0375)$ in the soleus muscle of the affected limb. The EMG amplitude of the tibialis anterior was reduced in the compromised limb $(p<0.0001)$. After the use of the TENS, a reduction in the Hmax/Mmax ratio $(p=0.0006)$ was observed leading to lower reflex excitability. However, after the cryotherapy intervention an increase of the Hmax/Mmax ratio was observed, which was accompanied by an increase in the $\mathrm{H}$-reflex latency ( $\mathrm{p}=0.0001)$. The EMG amplitude has not changed by any of the interventions. Conclusions: Our findings suggest that TENS may be a choice for immediate reduction of reflex excitability, whereas cryotherapy intervention may increase reflex excitability in hemiparetic subjects. However, none of the changes mediated by either intervention were able to modify the electrical activity in the antagonist muscle of the spastic muscle. This trial was registered in the Australian New Zealand Clinical Trials Registry (ANZCTR) - ACTRN12610000302055.
\end{abstract}

Keywords: physical therapy; transcutaneous electrical nerve stimulation; cryotherapy; EMG; muscle spasticity; H-reflex.

\section{Resumo}

Contextualização: O distúrbio da função motora e reflexa em pacientes acometidos por acidente vascular encefálico (AVE) causa impactos negativos na realização de padrões motores, comprometendo as atividades funcionais. Objetivos: Investigar os efeitos imediatos da estimulação elétrica nervosa transcutânea (TENS) e da crioterapia na excitabilidade reflexa e na atividade voluntária de sujeitos vítimas de AVE. Método: Estudo Crossover. O reflexo H máximo (Hmáx), a latência do reflexo H e a resposta motora máxima (Mmáx) do músculo solear e a eletromiografia (EMG) do músculo tibial anterior foram avaliados antes e após a aplicação de TENS, crioterapia e em condições de controle. Resultados: A razão Hmáx/Mmáx estava significativamente aumentada $(p=0,0245)$ e a latência do reflexo $H$ significativamente diminuída ( $p=0,0375)$ no músculo solear do membro afetado. A amplitude do sinal EMG do músculo estava significativamente reduzida no membro comprometido $(p<0,0001)$. Depois da TENS, houve uma diminuição da razão Hmáx/Mmáx $(p=0,0006)$. Porém, após a aplicação do gelo, houve um aumento da razão Hmáx/Mmáx, acompanhado por um aumento da latência do reflexo $H$ ( $p=0,0001)$. A amplitude do sinal EMG não foi alterada por nenhuma das intervenções. Conclusões: Nossos achados indicam que a TENS pode ser uma escolha para redução imediata da excitabilidade reflexa, enquanto a crioterapia pode aumentar a excitabilidade reflexa de sujeitos hemiparéticos. No entanto, nenhuma das alterações mediadas por qualquer um dos tratamentos foi capaz de alterar a atividade elétrica do músculo antagonista ao espástico.

Artigo registrado na Australian New Zealand Clinical Trials Registry (ANZCTR) sob o número ACTRN12610000302055.

Palavras-chave: fisioterapia; estimulação elétrica transcutânea; crioterapia; EMG; espasticidade; reflexo H.

Received: 02/22/2012 - Revised: 03/23/2012 - Accepted: 03/30/2012

'Physical Therapy Department, Centro Universitário de João Pessoa (UNIPÊ), João Pessoa, PB, Brazi

${ }^{2}$ Nucleus of Research in Human Movement Science, Universidade Federal da Paraíba (UFPB), João Pessoa, PB, Brazil

${ }^{3}$ Physical Therapy Department, Universidade Federal do Rio Grande do Norte (UFRN), Natal, RN, Brazil

Correspondence to: Ana Raquel Rodrigues Lindquist, Universidade Federal do Rio Grande do Norte, Av. Senador Salgado Filho, 3000, Caixa Postal 1524, CEP 59072-970, Natal, RN, Brasil,

e-mail: raquellindquist@ufrnet.br 


\section{Introduction $: \because$.}

Stroke occurs in the presence of acute neurological dysfunction caused by abnormal brain circulation. This provokes motor function and reflex disorders as a result of damage to focal areas of the brain ${ }^{1,2}$. Many of the limitations caused by stroke are related to spasticity. The condition is characterized by hyperexcitability of the velocity-dependent stretch reflex, exaggeration of deep tendon reflexes, increased muscle tonus and loss of movement control ${ }^{3,4}$. Among the many physiopathological mechanisms involved in spasticity, we highlight the effective loss of descending inhibitory influences, which increases excitability in gamma fusimotor neurons and alpha motor neurons ${ }^{5,6}$. In accordance with Dietz and Sinkjaer ${ }^{7}$, the hyperexcitability reflex in stroke patients interferes with motor function. This causes restricted and compromised movement control, limitations in standard functional movement necessary for daily activities and difficulties in progressing through rehabilitation.

Physical therapy uses resources such as cryotherapy $y^{8-11}$ and transcutaneous electrical nerve stimulation (TENS) ${ }^{12-15}$ in order to reduce the hyperexcitability in post-stroke patients and promote more coordinate movement control. Cryotherapy is considered a therapeutic resource of temporarily reducing spasticity symptoms. It consists of lowering the stretch sensitivity of neuromuscular spindles by reducing intrafusial fiber activity in the gamma system (decreasing nerve conduction velocity ${ }^{8,16}$. The TENS mechanisms of action are based on the hypothesis that it provokes an additional sensory input in the central nervous system (CNS), causing presynaptic inhibition of the suprasegmental pathways ${ }^{17}$.

Although the use of cryotherapy and TENS interventions aims to reduce neuromuscular excitability in spasticity, its mechanisms of action is still controversial. Examples of this can be found in studies by Price et al. ${ }^{9}$, and Chiara et al. ${ }^{18}$, where increased spasticity was observed after cooling, as well as in the study of Cramp et al. ${ }^{19}$ and Miller et al. ${ }^{20}$ whose results showed that TENS did not significantly alter neuromuscular excitability.

Results on the action of TENS and cryotherapy in the treatment of spasticity are conflicting, and studies on their short-term effects are scarce. Thus, the present study aims to investigate the excitability reflex of stroke patients and the immediate effects of TENS and cryotherapy interventions on this excitability in order to determine if a possible change in reflex excitability can influence motor function in the muscle opposite the spastic one. Our hypothesis is that these two treatments will reduce hyperexcitability in the spastic muscle, despite acting on different physiological mechanisms. This would facilitate a greater activity in the anterior tibialis muscle since the spastic muscle would be more relaxed.

\section{Method : :}

\section{Participants}

Twenty patients of both genders with post-stroke hemiparesis were selected. Inclusion criteria were: clinical diagnosis of stroke, minimum injury duration of 6 months, degree of spasticity for the soleus muscle between 1 and 3 on the modified Ashworth scale ${ }^{21}$, with scores ranging from 0 to 5 , where 0 represents no increase in muscle tone and 5 indicates the joint was rigid in flexion or extension position ${ }^{21}$, ability to understand simple verbal commands and absence of degenerative diseases or musculoskeletal injuries in the ankle joint. Hypersensitivity to ice or to electric stimulation, inability to tolerate the intensity of the electric current used to evaluate the H-reflex and maximum motor response (Mmax) and non-attendance at the three assessment days were established as exclusion criteria.

All subjects were informed of the data collection procedures and gave their informed written consent to participate in this study. The study was approved by the Research Ethics Committee of the Universidade Federal do Rio Grande do Norte (UFRN), Natal, RN, Brazil, under protocol n. 109/2009.

\section{Assessment and intervention instruments}

In order to evaluate the H-reflex, the Mmax response and surface electromyography (EMG) of the anterior tibialis muscle, a custom-made amplifier was used, based on an amplifier (INA121, Texas Instruments). Common-mode rejection of the biological amplifier is $>110 \mathrm{~dB}$ and a bandwidth between 10 and $490 \mathrm{~Hz}$. Gain can be selected for values of $350,750,1500,3000^{22,23}$.

Posterior tibialis nerve stimulation was performed with a biological electro stimulator that produces constant rectangular voltage pulses of up to 180 volts with a duration of $0.5 \mathrm{~ms}$, to generate an evoked response. BioMed digital polygraph software was used to capture, visualize, store and process signals both on-and-off line ${ }^{24,25}$.

Skin temperature before and after ice application was measured with a K type thermocouple, connected to an ET-2100 digital multimeter (Minipa). The thermocouple operates in the $20-750^{\circ} \mathrm{C}$ range, with $3 \%$ precision in the 0 to $750^{\circ} \mathrm{C}$ range. 


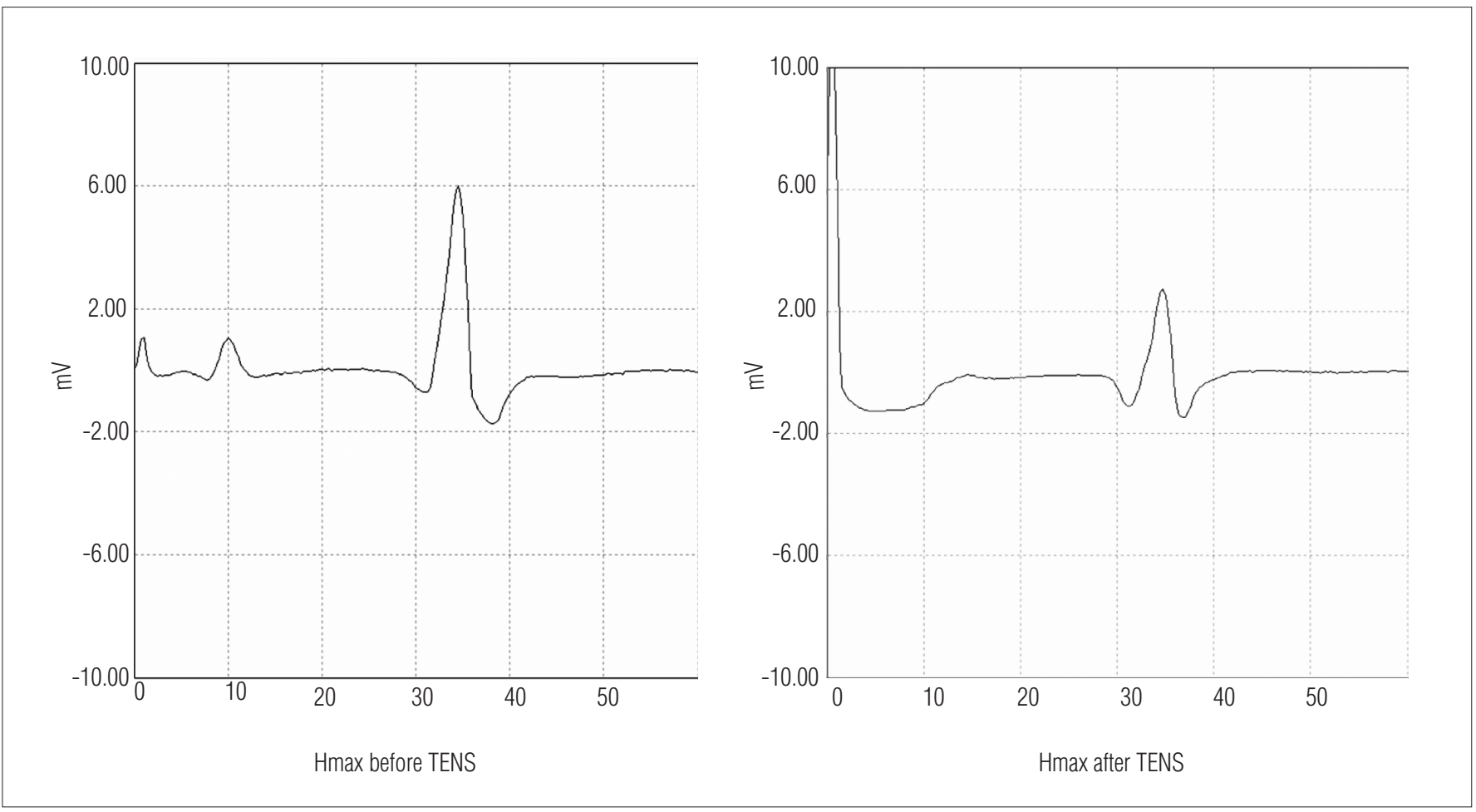

Figure 1. Hmax after and before application of TENS.
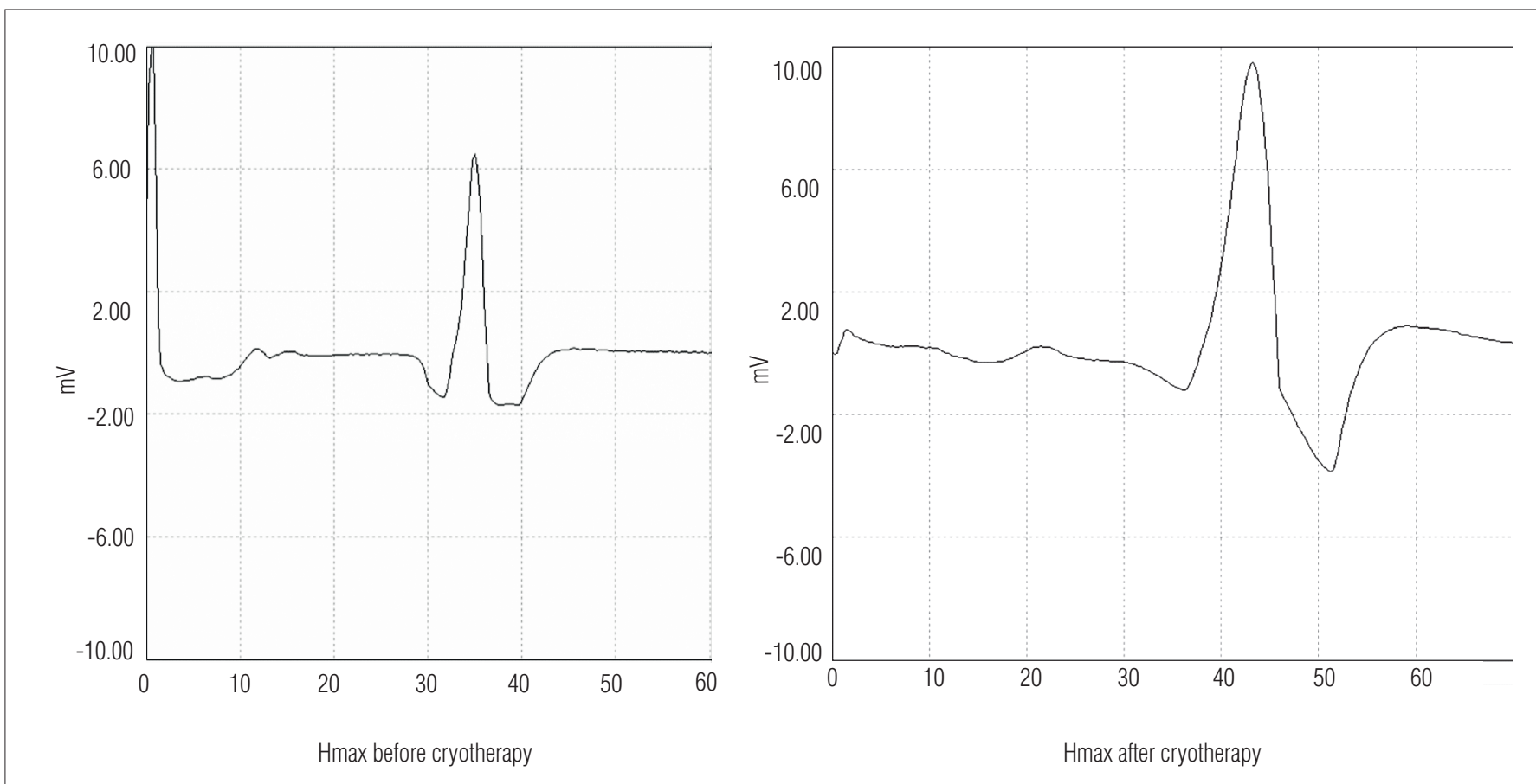

Figure 2. Hmax after and before application of cryotherapy.

For TENS application we used sensory level stimulation, obtained by 2-channel VIF 993 portable TENS equipment (QUARK), with adjustable frequency between 5 and $100 \mathrm{~Hz}$ and pulse duration of 2 to $200 \mu \mathrm{s}$.

Cryotherapy was performed using ice compresses consisting of approximately $2 \mathrm{~kg}$ of crushed ice in 5 -liter bags.

\section{Experimental design}

The present study has a randomized crossover design, where subjects were evaluated over three days. One day was used for control procedures and the remaining two for intervention (Cryotherapy and TENS). Lots were drawn to 
determine the order for the interventions and control. For control procedures, the compromised limb of volunteers was assessed twice, with an interval of 30 minutes between evaluations. On both non-consecutive intervention days, the limb was examined before and immediately after a 30-minute session of cryotherapy, as well as prior to and directly following a 30-minute TENS application.

\section{Data acquisition}

\section{Recording of H-reflex and Mmax response}

Volunteers sat on a chair with their knee semiflexed at an angle of approximately $70^{\circ}$ and their ankle at $90^{\circ}$. The H-reflex was recorded after stimulation of the posterior tibialis nerve in the popliteal fossa, with a pen-shaped metallic ball-point negative electrode, which facilitated reaching the stimulation location. The positive electrode consisted of a metallic mesh introduced into a water-moistened sponge, placed on the anterior surface of the patella and fixed with adhesive tape.

In order to record the H-reflex and $\mathrm{M}$-wave, two $\mathrm{Ag} / \mathrm{AgCl}$ surface recording bar electrodes (SKINTACT) were placed over the soleus muscle. These were situated at $4 \mathrm{~cm}$ and $6 \mathrm{~cm}$ distal to the lower contour of the gastrocnemius muscle. The reference electrode was located on the medial malleolus contralateral to the limb being examined.

The signal was amplified using a 350 gain and digitized by a sampling frequency of $4000 \mathrm{~Hz}$ with 12 bits resolution. The BioMed program triggers a screen scan at a 3.5-volt threshold of a 5 volts synchronization pulse, issued simultaneously to tibialis nerve stimulation.

Maximum H-reflex was recorded starting with minimum pulse stimulation amplitude, increasing at $10 \mathrm{~s}$ intervals until maximum peak-to-peak amplitude (Hmax) was reached. Once Hmax was registered, intensity continued to be increased until maximum peak-to-peak $\mathrm{M}$ response (Mmax) was achieved. Hmax reflex, Mmax response and H-reflex latency were automatically determined by a Biomed digital polygraph. H-reflex normalization was obtained by dividing its peak-to-peak amplitude by the peak-to-peak amplitude of the maximum $\mathrm{M}$ response (Hmax/Mmax ratio).

\section{EMG of the anterior tibialis muscle}

With the volunteers in the sitting position, surface electrodes were placed over the tibialis anterior muscle according to SENIAM (Surface Electromyography for the Non-Invasive Assessment of Muscles) recommendations, positioned at 1/3 the distance from the line between the fibula and the medial malleolus. The reference electrode was fixed on the medial malleolus of the contralateral limb. Surface EMG was digitized at a sampling frequency of $1000 \mathrm{~Hz}, 12$ bits resolution and 1500 gain. Five seconds of signal was recorded during maximum voluntary isometric contraction (MVIC), followed by $90 \mathrm{~s}$ of rest. MVIC was repeated 3 times, taking into account the highest RMS value of the three contractions.

The signal was processed using a notch filter with a center frequency of $60 \mathrm{~Hz}$. The RMS (Root Mean Square) was calculated after obtaining the absolute value of the signal in order to facilitate visualization and selection of a 2-second period from a total 5 -second contraction. When data from the same individual were compared (intra-session), normalization was not necessary. However, when compared between interventions (inter-session), normalization occurred by dividing postintervention RMS value by the pre-intervention value.

\section{Application of TENS and cryotherapy}

TENS was used in a conventional manner, with a frequency of $100 \mathrm{~Hz}^{14}$ and pulse duration of $60 \mu$ s for 30 minutes at sensory level, with the patient in dorsal decubitus. Two pairs of $5 \mathrm{~cm} \times 5 \mathrm{~cm}$ electrodes were placed over the S1 and S2 dermatomes (gastrocnemius and solear), the sensory root of the posterior tibialis nerve. Amplitude of the stimulus was adjusted at the maximum sensorial level tolerated by the participant without pain or reaching the motor threshold. Cryotherapy (ice compresses) was applied over the gastrocnemius and soleus muscles for 30 minutes, with the volunteer in the dorsal decubitus position.

\section{Statistical analysis}

The entire data set analyzed presented normal distribution. The paired Student t-test was used to compare the affected and non-affected limb before and after each intervention. Analysis of variance for related samples (ANOVA) was used to compare the results between TENS, cryotherapy and control conditions. Once the differences between interventions were identified, Tukey's post hoc test was used to identify which measurements were statistically significant.

\section{Results : :}

Twenty volunteers took part in the sample; however, a sample loss of 4 participants occurred because of difficulty 
Table 1. Normalized H-reflex, H-reflex latency and EMG before and after intervention.

\begin{tabular}{lcccccc}
\hline & Pre TENS & Post TENS & Pre Cryotherapy & Post Cryotherapy & Pre Control & Post control \\
Mean \pm SD & Mean \pm SD & Mean \pm SD & Mean \pm SD & Mean \pm SD & Mean \pm SD \\
\hline Hmax/Mmax & $0.60 \pm 0.18$ & $0.49^{*} \pm 0.16$ & $0.58 \pm 0.15$ & $0.77^{\star} \pm 0.13$ & $0.60 \pm 0.13$ & $0.60 \pm 0.13$ \\
\hline Latency $(m s)$ & $30.72 \pm 2.99$ & $30.81 \pm 1.66$ & $30.41 \pm 1.87$ & $33.24^{*} \pm 2.19$ & $30.37 \pm 1.63$ & $30.41 \pm 1.63$ \\
\hline RMS/EMG $(\mu \mathrm{V})$ & $209 \pm 83$ & $218 \pm 85$ & $218 \pm 69$ & $232 \pm 92$ & $205 \pm 64$ & $198 \pm 65$ \\
\hline
\end{tabular}

$\mathrm{SD}=$ standard deviation; $\mathrm{p}<0.05$ pre versus post; ${ }^{*} \mathrm{p} \leq 0.05$.

Table 2. Comparison between TENS, cryotherapy and control.

\begin{tabular}{lccc}
\hline $\begin{array}{l}\text { Comparison between } \\
\text { interventions }\end{array}$ & $\begin{array}{c}\text { Hmax/Mmax } \\
\mathrm{p}<0.0001\end{array}$ & $\begin{array}{c}\text { Latency } \\
\mathrm{p}<0.0001\end{array}$ & EMG \\
\hline Pre-TENS vs Pre-cryotherapy & $\mathrm{ns}$ & $\mathrm{ns}$ & $\mathrm{ns}$ \\
\hline Pre-TENS vs Control & $\mathrm{ns}$ & $\mathrm{ns}$ & $\mathrm{ns}$ \\
\hline Pre-cryotherapy vs Control & $\mathrm{nS}$ & $\mathrm{nS}$ & $\mathrm{nS}$ \\
\hline Post-TENS vs Post-cryotherapy & $\mathrm{p}<0.01$ & $\mathrm{p}<0.01$ & $\mathrm{~ns}$ \\
\hline Post-TENS vs Control & $\mathrm{p}<0.05$ & $\mathrm{~ns}$ & $\mathrm{~ns}$ \\
\hline Post-cryotherapy vs Control & $\mathrm{p}<0.01$ & $\mathrm{p}<0.01$ & $\mathrm{~ns}$ \\
\hline ns=non significant. & & &
\end{tabular}

in tolerating the electrical stimulus to measure the H-reflex and the M-response. Of the 16 subjects, 6 were men and 10 women. With regard to type of stroke, ischemic etiology was present in 14 and hemorrhagic in 2 participants. Mean age was 55.2 years-old (SD 9.9) and mean injury duration was 62.3 months (SD 49.3). In relation to the Ashworth scale, volunteers presented a mean of 1.93 (SD 0.77).

\section{Comparison between affected and non-affected limb}

A statistically significant increase was recorded in the Hmax/Mmax ratio of the affected limb when compared with the same ratio in the control $(0.475 \pm 0.188$ versus $0.603 \pm 0.135$; $\mathrm{p}=0.0245)$. H-reflex latency showed a higher mean in the non-affected limb compared to the affected limb, statistically significant decrease $(31.15 \pm 2.06 \mathrm{~ms}$ versus $30.39 \pm 1.62 \mathrm{~ms}$; $\mathrm{p}=0.0375$ ). The RMS value of the tibialis muscle EMG in the non-affected limb was higher than that of the affected limb, with a statistically significant difference $(337.62 \pm 118.7 \mu \mathrm{V}$ versus $201.68 \pm 64.7 \mu \mathrm{V}$; $\mathrm{p}<0.0001)$.

\section{Changes in soleus H-reflex and TA EMG in TENS, cryotherapy and control conditions}

Results showed a statistically significant reduction in the Hmax/Mmax ratio $(\mathrm{p}=0.0006)$ after TENS application (Figure 1). With respect to cryotherapy, a statistically significant increase was observed in the Hmax/Mmax ratio ( $\mathrm{p}=0.0007)$ after soleus muscle cooling (Figure 2). Prior to ice application, mean temperature of the patients' skin was $29.2^{\circ} \mathrm{C} \pm 1.2^{\circ} \mathrm{C}$. After 30 min of ice compress application, skin temperature dropped to mean values of $8.5^{\circ} \mathrm{C} \pm 1.7^{\circ} \mathrm{C}$. In the control, no significant differences were observed in the Hmax/Mmax ratio before and after the 30-min period (Table 1).

Following TENS application in the control experiment, no significant differences were detected in H-reflex latency. However, cryotherapy led to a decrease in nerve conduction velocity, expressed by greater H-reflex latency ( $p=0.0001)$. No significant differences in H-reflex latency were observed in the control (Table 1).

RMS values of EMG in the tibialis anterior muscle showed no significant differences after intervention with TENS, cryotherapy or control (Table 1).

\section{Comparison between TENS, cryotherapy and control conditions}

The ANOVA test established that when Hmax/Mmax ratio and H-reflex latency values were compared between post-TENS and post-cryotherapy, post-TENS and control and post-cryotherapy and control, a statistically significant difference was found $(\mathrm{p}<0.0001)$ (Table 2).

\section{Discussion $: \because$.}

The present study recorded an increase in the Hmax/ Mmax ratio and reduction in the H-reflex latency in the affected limb in patients affect by stroke. This indicates that individuals suffering from spasticity present high excitability in pathways involving the stretch reflex, culminating in an exacerbated response on application of an external stimulus.

The increase in the H-reflex amplitude is the most excitable expression of the alpha motor neuron that is not inhibited in stroke victims ${ }^{26,27}$. This excitability, established by the increase in the Hmax/Mmax ratio, begins within a few months of the cerebrovascular lesion and is associated with higher muscle tonus, hyperreflexia and changes over time in the viscoelastic properties of the affected muscles ${ }^{28}$. However, according to Levin and Hui-Chan ${ }^{29}$, the Hmax/Mmax ratio increase does not necessarily co-exist and is not associated to other spasticity characteristics. 
Furthermore, Hui-Chan and Levin ${ }^{30}$ stated that in addition to the increase in reflex response, subjects affected by spasticity demonstrated reduced H-reflex latency. This may also be related to the decreased reflex threshold. A study by Bakheit et al. ${ }^{5}$, evaluated 24 adult victims of hemorrhagic and ischemic strokes. Participants were divided into two groups according to their evaluation score on the Ashworth scale. The study found a lower H-reflex latency in both groups.

RMS value of the anterior tibialis muscle EMG in the affected limb was substantially reduced when compared with the unaffected limb. This suggests a neuromuscular deficit in the paretic muscle of these patients, likely due to lower recruitment and discharge in muscle units, impaired reciprocal inhibition and physiological changes, such as alterations in the viscoelastic properties of the tissue, greater numbers of slow muscle fibers and muscular shortening ${ }^{31-33}$.

\section{TENS}

The decreased Hmax/Mmax ratio following TENS application suggests that this treatment led to a reduction in the motor neuron excitability. One of the primary justifying hypotheses for this hyperexcitability is the lack of presynaptic inhibition and/or a change in Renshaw cell activity. These alterations may be caused by a loss of supraspinal control. In these conditions, treatment that aims to modulate the excessive impulses or the system of inter neurons becomes useful ${ }^{34}$. Activating large diameter afferent nerve fibers through TENS may modulate interneuron activities in several spinal segments, which then activate inhibition mechanisms of the presynaptic nerve ${ }^{17}$. An alternative hypothesis is that somatosensory stimulation through TENS due to continuous activation of peripheral nerve fibers causes insensitivity to prolonged central excitation accompanied by lower corticomotor neuron excitability (refractoriness) $^{35,36}$.

In his clinical study, Aydin et al. ${ }^{14}$ included spasticity patients who suffered spinal cord injury. Participants were divided into three groups: 11 individuals used TENS at a frequency of $100 \mathrm{~Hz}$ and $100 \mu$ s in 15 daily sessions, 10 patients took oral doses of Baclofen and 20 healthy individuals were assigned as controls. Groups were then compared using clinical, electrophysiological and functional measures. Results showed an improvement in spasticity in both active groups. Evaluations were carried out using a modified Ashworth scale and peak amplitude of the H-reflex. Clinical and electrophysiological changes and functional variables found with baclofen, a medication with proven spasticity-reducing effects, were no different to physiological changes caused by TENS.
Considering immediate effects of TENS, Hui-Chan and Levin ${ }^{30}$ suggested that segmental afferent manipulation after a single TENS session at a frequency of $99 \mathrm{~Hz}$ and pulse duration of $0.125 \mathrm{~ms}$ is the cause of the reduced stretch reflex excitability, which is greater in individuals with hemiparesis. Potisk, Gregoric and Vodovnik ${ }^{12}$ and Levin and Hui-Chan ${ }^{13}$ showed that the therapeutic benefits of TENS not only involve reduced spasticity, but also improved voluntary control during motor tasks. This may be partly due to the improvement in presynaptic inhibition, as well as the dis-inhibition of descending voluntary commands to the motor neurons of paretic muscles.

Although our study presents methodological differences to the two previously mentioned studies, primarily in relation to the type of muscular contraction used, we expected that in decreasing spastic muscle activity and thereby lowering co-contraction, activity in its antagonist (anterior tibialis) would increase during a CIVM. However, although TENS provokes reduced neuromuscular excitability, there was no alteration in the EMG of the anterior tibialis muscle. This probably occurred because some or all of the pathways contributing to reciprocal inhibition appear to not function adequately following an upper motor neuron lesion. This is likely caused by the loss of tonic supraspinal impulses to segmentary circuits or lack of voluntary activation in this system ${ }^{12,17}$.

\section{Cryotherapy}

In addition to the increase in H-reflex amplitude, we observed an increase in the H-reflex latency, caused by nerve conduction velocity reduction due to cooling ${ }^{16,37,38}$. Similar results were found by Dewhurst et al. ${ }^{39}$, who assessed the H-reflex after cooling in a sample of 10 young and 10 elderly women. The results suggest H-reflex facilitation in young women, evidenced by the increased Hmax/Mmax ratio. A study by Price et al..$^{9}$ determined ambiguous results, that is, although a tendency of lower spasticity was observed, two subjects showed worse spasticity.

With regards to the increase in the H-reflex latency, a linear relationship between skin temperature and nerve conduction velocity has been demonstrated; that is, as the nerve fiber gets cooler, nerve conduction velocity decreases. Unidirectionally, higher latency may be an important variable for showing that ice application is beneficial in reducing spasticity effects; however, this increase was associated with an increase in peak-to-peak H-reflex amplitude, contributing to the greater Hmax/Mmax ratio. It is important to consider the influence of cooling on other conduction variables such as amplitude and nerve conduction duration, 
which may increase after cooling and exacerbate reflex responses ${ }^{40,41}$. Conversely, Allison and Abraham ${ }^{8}$ state that the H-reflex elevation after cooling should not be misinterpreted. These authors suggest that inhibitory mechanisms such as presynaptic and reciprocal inhibition are damaged by cold, while other measures may promote improvements in spasticity.

According to Dewhurst et al. ${ }^{39}$, and Sandoval Ortiz ${ }^{40}$, the mechanism responsible for increasing H-reflex during local cooling might be explained by greater synchronism of prolonged depolarization in afferent fibers. It has been suggested that a change in temperature alters the opening and closing duration of sodium channels along the axon. Thus, cooling reduces depolarization velocity, allowing more sodium to enter the cell, increases latency, amplitude and action potential duration. Lightfoot et al. ${ }^{10}$ maintains that configuration changes occur in the M-wave due to lower motor nerve conduction as cooling progresses, altering the Hmax/Mmax ratio.

Lima $^{42}$ analyzed the Hmax and the Mmax reflexes in 14 patients suffering from hemiplegia and spasticity at 2.5; 5 ; 10 and 20 min during cooling. Findings indicate a reduction in maximum the H-reflex peak-to-peak amplitudes and increased latencies throughout cooling. Although the study applies similar methodology for H-reflex measurement and total cryotherapy application time, there was a difference in relation to the present study for the moment of H-reflex measurement, which occurred simultaneously to cooling. This study measured the H-reflex immediately after ice application, suggesting that the increased Hmax/Mmax ratio may occur as a rebound effect.
RMS value of the EMG of the anterior tibialis muscle following cryotherapy and TENS showed no changes, indicating that the higher Hmax/Mmax ratio neither did not alter or was insufficient to alter electromyography activity in the anterior tibialis.

In contrast to our results, Harlaar et al. ${ }^{11}$ found altered EMG after 20 minutes of cooling in the gastrocnemius muscle. However, it is important to note that EMG changes occurred in the cooled muscle and the increased electrical activity did not result in functional gain.

Results obtained in this study lead us to conclude that post-stroke patients present neuromuscular hyperexcitability characterized by an increase in the Hmax/Mmax ratio and decreased H-reflex latency. We also conclude that transcutaneous electrical nerve stimulation may be an important modality for temporarily reducing spasticity. A greater H-reflex response was recorded in cryotherapy, contributing to a increase in the Hmax/Mmax ratio. We also found that none of the alterations provoked by TENS and cryotherapy were able of changing electrical activity in the muscle antagonist to the spastic muscle. This demonstrates that other characteristics inherent to spasticity may have a more determinative contribution to impaired motor function.

In light of limitations in the present study, we suggest that future investigations use a larger and more homogeneous sample, as well as a submaximum H-reflex of $20 \%$ to $30 \%$ of the M-wave. This will avoid underestimation of spinal excitability changes and seeks to evaluate motor function of the spastic muscle under the acute effect of these modalities, as well as complex motor function such as gait.

\section{References: : :}

1. Pfister AA, Roberts AG, Taylor HM, Spaudling SN, Damian MM, Charles PD. Spasticity in adults living in a developmental center. Arch Phys Med Rehabil. 2003:84(12):1808-12.

2. Kumar RTS, Pandyan AD, Sharma AK. Biomechanical measurement of post-stroke spasticity. Age Ageing. 2006;35(4):371-5

3. Sommerfeld DK, Eek EUB, Svensson AK, Holmqvist IW, Arbin MH. Spasticity After stroke: its occurrence and association with motor impairments and activity limitations. Stroke. 2004;35(1):134-9

4. Pisano F, Miscio G, Del Conte C, Pianca D, Candeloro E, Colombo R. Quantitative measures of spasticity in post-stroke patients. Clin Neurophysiol. 2000;111(6):1015-22.

5. Bakheit AMO, Maynard VA, Curnow J, Hudson N, Kodapala SK. The relation between Ashworth scale scores and the excitability of the alfa motor neurones in patients with post-stroke muscle spasticity. J Neurol Neurosurg Psychiatry. 2003;74(5):646-8.

6. Morita H, Crone C, Christenhuis D, Petersen NT, Nielsen JB. Modulation of presynaptic inhibition and disynaptic reciprocal la inhibition during voluntary movement in spasticity. Brain. 2001;124(Pt 4):826-37.
7. Dietz V, Sinkjaer T. Spastic movement disorder: impaired reflex function and altered muscle mechanics. Lancet Neurol. 2007;6(8):725-33.

8. Allison SC, Abraham LD. Sensitivity of qualitative and quantitative spasticity measures to clinical treatment with cryotherapy. Int J Rehabil Res. 2001;24(1):15-24.

9. Price R, Lehmann JF, Boswell-Bessette S, Burleigh A, deLateur BJ. Influence of cryotherapy on spasticity at the human ankle. Arch Phys Med Rehabil. 1993;74(3):300-4.

10. Lightfoot E, Verrier M, Ashby P. Neurophysiological effects of prolonged cooling of the calf in patients with complete spinal transection. Phys Ther. 1975;55(3):251-8.

11. Harlaar J, Ten Kate JJ, Prevo AJ, Vogelaar TW, Lankhorst GJ. The effect of cooling on muscle co-ordination in spasticity: assessment with the repetitive movement test. Disabil Rehabil. 2001;23(11):453-61.

12. Potisk KP, Gregoric M, Vodovnik L. Effects of transcutaneous electrical nerve stimulation (TENS) on spasticity in patients with hemiplegia. Scand J Rehabil Med. 1995;27(3):169-74.

13. Levin MF, Hui-Chan CW. Relief of hemiparetic spasticity by TENS is associated with improvement in reflex and voluntary motor functions. Electroencephalogr Clin Neurophysiol. 1992;85(2):131-42. 
14. Aydin G, Tomruk S, Keles I, Zbudak S0, Orkun S. Transcutaneous electrical nerve stimulation versus baclofen in spasticity: Clinical and electrophysiologic comparison. Am J Phys Med Rehabil. 2005;84(8):584-92

15. Sonde L, Kalimo H, Viitanen M. Stimulation with high-frequency TENS - Effects on lower limb spasticity after stroke. Adv Physiother. 2000;2(4):183-7.

16. Swenson C, Swärd L, Karlsson J. Cryotherapy in sports medicine. Scand J Med Sci Sports. 1996;6(4):193-200.

17. Wang RY, Chan RC, Tsai MW. Effects of thoraco-lumbar electric sensory stimulation on knee extensor spasticity of persons who survived cerebrovascular accident (CVA). J Rehabil Res Dev. 2000;37(1):73-9

18. Chiara T, Carlos JJr, Martin D, Miller R, Nadeau S. Cold effect on oxygen uptake, perceived exertion, and spasticity in patients withmultiple sclerosis. Arch Phys Med Rehabil. 1998;79(5):523-8.

19. Cramp FL, Noble G, Lowe AS, Walsh DM, Willer JC. A controlled study on the effects of transcutaneous electrical nerve stimulation and interferential therapy upon RIII nociceptive and H-reflexes in humans. Arch Phys Med Rehabil. 2000;81(3):324-33.

20. Miller L, Mattison P, Paul L, Wood L. The effects of transcutaneous electrical nerve stimulation (TENS) on spasticity in multiple sclerosis. Mult Scler. 2007;13(2):527-33.

21. Bohannon RW, Smith MB. Interrater reliability of a modified Ashworth Scale of muscle spasticity. Phys Ther. 1987;67(2):206-7.

22. Rodrigues SA. Desenvolvimento de instrumentação e software para a aquisição e processamento de sinais reflexos. [Dissertação]. João Pessoa: UFPB; 1994.

23. Rodrigues AS, Carvalho LC, Costa MM. Desenvolvimento de instrumentação e software para aquisição e processamento de sinais reflexo. Rev Bras Eng Biomed. 1996;12(2):47-72.

24. Carvalho LC, Motta GHMB, Duarte NB, Fernandes MR, Fernandes FCA. Windows based software tool for use on physiological experiments. World Congress on Medial Physycs Biomedical Engineering; 1997; Nice/França. Medical \& Biological \& Engineering \& Computing. 1997.

25. Carvalho LC, Lima RB, Duarte NB, Fernandes MR, Nóbrega AC, Batista LV. Software em Windows para processamento, armazenamento e análise de sinais obtidos em experimentos de fisiologia. Anais do ler Congreso Latinamericano de Ingeniería Biomédica; 1998.

26. Funase K, Miles TS. Observations on the variability of the H-reflex in human soleus. Muscle Nerve. 1999;22(3):341-6.

27. Goulart F, Valls-Sole J, Alvarez R. Posture-related changes of soleus H-reflex excitability. Muscle Nerve. 2000;23(6):925-32.

28. Fischer MA. H reflexes and $\mathrm{F}$ waves. Fundamentals, normal and abnormal patterns. Neurol Clin. 2002;20(2):339-60, vi.
29. Levin MF, Hui-Chan $\mathrm{C}$. Are $\mathrm{H}$ and stretch reflexes in hemiparesis reproducible and correlated with spasticity? J Neurol. 1993;240(2):63-71.

30. Hui-Chan C, Levin MF. Stretch reflex latencies in spastic hemiparetic subjects are prolonged after transcutaneous electrical nerve stimulation. Can J Neurol Sci. 1993;20(2):97-106.

31. Junqueira RT, Ribeiro AMB, Scianni AA. Efeitos do fortalecimento muscular e sua relação com a atividade funcional e a espasticidade em indivíduos hemiparéticos. Rev Bras Fisioter 2004;8(3):247-52.

32. Leonard CT, Diedrich PM, Matsumoto T, Moritani T, McMillan JA. H-reflex modulations during voluntary and automatic movements following upper motor neuron damage. Electroencephalogr Clin Neurophysiol. 1998;109(6):475-83.

33. Carr JR, Shepherd RB. Neurological Rehabilitation: Optimizing Motor Performance. $2^{\text {nd }}$ ed Oxford: Butterworth Heinemann; 2000.

34. Lamy JC, Wargon I, Mazevet D, Ghanim Z, Pradat-Diehl P, Katz R. Impaired efficacy of spinal presynaptic mechanisms in spastic stroke patients. Brain. 2009;132(Pt 3):734-48.

35. Tinazzi M, Zarattini S, Valeriani M, Romito S, Farina S, Moretto G, et al. Long-lasting modulation of human motor cortex following prolonged transcutaneous electrical nerve stimulation (TENS) of forearm muscles: evidence of reciprocal inhibition and facilitation. Exp Brain Res. 2005;161(4):457-64.

36. Mima T, Oga T, Rothwell J, Satow T, Yamamoto J, Toma K, et al. Short-term high-frequency transcutaneous electrical nerve stimulation decreases human motor cortex excitability. Neurosci Lett. 2004;355(1-2):85-8.

37. Lee SU, Bang MS, Han TR. Effect of cold air therapy in relieving spasticity: applied to spinalized rabbits. Spinal Cord. 2002;40(4):167-73.

38. Chesterton LS, Foster NE, Ross L. Skin temperature response to cryotherapy. Arch Phys Med Rehabil. 2002;83(4):543-9.

39. Dewhurst S, Riches PE, Nimmo MA, De Vito G. Temperature dependence of soleus H-reflex and M wave in young and older women. Eur J Appl Physiol. 2005;94(5-6):491-9.

40. Sandoval Ortiz MC. Efectos fisiológicos de la crioterapia. Rev Univ Ind Santander Salud 2007;39(1):59-70.

41. Santuzzi CH, Gonçalves WLS, Rocha SS, Castro MEC, Gouvea AS, Abreu GR. Efeitos da crioterapia, estimulação elétrica transcutânea e da sua associação na atividade elétrica do nervo femoral em ratos. Rev Bras Fisioter. 2008;12(6):441-6.

42. Lima SS. Estudo do comportamento do músculo solear do paciente hemiplégico espástico submetido a um resfriamento por gelo, através do EMG superficial [Dissertação]. João Pessoa: UFPB; 2005. 